(C) 2017, Elsevier. Licensed under the Creative Commons AttributionNonCommercial-NoDerivatives 4.0 International

http: //creativecommons.org/licenses/by-nc-nd/4 .0/

\title{
EFFECT OF TEMPERATURE ON PRODUCT PERFORMANCE OF A HIGH ASH BIOMASS DURING FAST PYROLYSIS AND ITS BIO-OIL STORAGE EVALUATION
}

\author{
N. Gómez ${ }^{\text {a }}$ S.W. Banks ${ }^{\text {, D.J. Nowakowski }}{ }^{\text {, J.G Rosas }}{ }^{\mathrm{a}}$, J. Cara $^{\mathrm{a}}$, M.E. Sánchez ${ }^{\mathrm{a}, \mathrm{c}}$, \\ A.V. Bridgwater ${ }^{\text {b }}$ \\ ${ }^{a}$ Natural Resources Institute, Chemical and Environmental Engineering Group, University of León. \\ Avda. de Portugal 41, 24071 León, Spain \\ ${ }^{\mathrm{b}}$ European Bioenergy Research Institute, Aston University, Birmingham B4 7ET, United Kingdom \\ ${ }^{\mathrm{c}}$ Corresponding author
}

\section{Highlights:}

The conjunction of temperature and $\mathrm{K}$ content affects mass and energy distribution Low pyrolysis temperatures reduce water in bio-oils avoiding phase separation Pyrolysis of a high ash biomass (with high $\mathrm{K}$ content) tends to form phenols Storage tests showed a degradative behavior in bio-oils

\section{Keywords:}

Bio-oil, high ash biomass, storage test, mass and energy distribution

\begin{abstract}
Bio-oil from the fast pyrolysis of agro-residues still need to contemplate different production scenarios to look for its feasibility. For this reason, in this work the effect of a range of fast pyrolysis temperature $\left(450,480,510\right.$ and $\left.550{ }^{\circ} \mathrm{C}\right)$ processing rape straw biomass (with high $\mathrm{K}$ content) has been studied in a continuous bubbling fluidised bed reactor. It was found that the catalytic effect of the inorganic content was different at each fast pyrolysis temperature, with the lower temperatures resulting in the highest yield of biooil due to minor catalytic effect (up to $41.39 \mathrm{wt}$. \%). It was also found that at $480{ }^{\circ} \mathrm{C}$ the bio-oil presented the best combination of physico-chemical features such as non-separation
\end{abstract}


phase and the lowest water content; yield (39.65 wt. \%) and HHV (19.23 MJ/kg), containing a high concentration of phenolic compounds. At the fast pyrolysis temperature of $510^{\circ} \mathrm{C}$ and $550^{\circ} \mathrm{C}$, the conjunction effect of temperature and the catalytic effect provoked bio-oil separation into two phases and a higher gas yield than was expected. Then, the higher temperatures are not suitable for bio-oil production. Char is also an interesting co-product for all pyrolysis temperatures.

\section{INTRODUCTION}

Alternative energy demand through bioenergy processes is increasing in a current society that worries about the environmental impacts of the use of fuels. Fast pyrolysis is a thermal depolymerisation process in the absence of air yielding three products: a liquid fraction (biooil), a solid fraction (char) and a gaseous fraction (non-condensable gases), with the production of bio-oil being the focus. This technology produces biofuels from lignocellulosic biomass and can be used to manage biomass residues resulting in a dual benefit. It is a promising alternative for producing valuable products from renewable resources, as well as reducing the $\mathrm{CO}_{2}$ carbon footprint and there is a large availability. Moreover, if they come from residues they can be properly removed.

The conditions that evolved fast pyrolysis are: high heating rates and very high heat transfer rates; careful control of the temperature typically $500{ }^{\circ} \mathrm{C}$; short hot vapour residence times $(<2 s)$; rapid removal of char and rapid cooling of pyrolysis vapours [1]. Bio-oil yield is feedstock dependent as each biomass has a different proportion of its main components, cellulose, hemicellulose and lignin [2]. All three main components result in a variety of decomposition pathways during fast pyrolysis producing a complex combination of products in the vapour phase [3]. The bio-oil constituents are typically oxygenated compounds that can be potentially used as fuels or sources of value-added compounds [4], whilst the char and non-condensable gases can also be used as fuels.

Previous studies have shown that woody biomass has better properties for bio-oil production at the same pyrolysis temperature [5]. Nonetheless, agricultural crop residues 
would be an interesting source of biomass feedstock for thermal processes because it generates high amount of residues that should be correctly managed through the "energy from waste" concept. This type of biomass is commonly linked with high ash content [6], which has been linked to lower bio-oil production as it provokes phase separation in biooils occurring due to the catalytic effect of the inorganic matter during the fast pyrolysis reactions [1]. There are some studies about minimising inorganic matter within biomass by pretreatment [7], [8],[9] , [10], etc. However these practices result in higher processing costs and do not solve other issues of bio-oil characteristics. Experimental evaluation of pyrolysis temperatures has been done before in slow pyrolysis to explain biomass behavior and how they affect yields such as [11], [12]. Focusing on fast pyrolysis, this work aims to study the effect of temperature $\left(450{ }^{\circ} \mathrm{C}, 480{ }^{\circ} \mathrm{C} 510^{\circ} \mathrm{C}\right.$ and $\left.550{ }^{\circ} \mathrm{C}\right)$ within a fluid bed fast pyrolysis reactor has on processing high ash content feedstock, in this case rape straw (>6 wt. $\%$ ash content). The objective is to conclude if controlling the temperature can minimise the effect of inorganic matter has on bio-oil yields and their characteristics, for their subsequently upgrading through hydrodeoxygenation, catalytic cracking, emulsification, steam reforming [13] and get clean fuels or chemicals. Thus, the novelty of this work is to evaluate the real behavior of high ash biomass in a semi-pilot reactor finding their most suitable bio-oil production condition previous to their upgrading. The chemical composition of the fast pyrolysis products, the physical properties of bio-oil and the energy product distribution are priorities of this work. In addition, bio-oil stability has been analysed to assess how its final composition would affect its behavior in long term storage, for their management either for upgrading or direct use as the principal product of fast pyrolysis.

\section{MATERIALS AND METHODS}

\subsection{Materials}

The rape straw was grown at Villaturiel village, province of Leon (Spain). The rape straw was dried in a greenhouse for a period of $24 \mathrm{~h}$ to reduce the moisture content to $11 \mathrm{wt}$. \%. The material was then submitted to three different cutting processes as pretreatment to achieve specific particle size fractions for fast pyrolysis processing $(0.25-2 \mathrm{~mm})$ and biomass characterisation $(0.15-0.25 \mathrm{~mm})$. 


\subsection{Thermogravimetric studies}

Thermogravimetric analysis was carried out using a PerkinElmer Pyris 1 thermobalance, following the standard ASTM E1131-03[14]. Different samples of 5.0 $\pm 0.1 \mathrm{mg}$ were pyrolysed at five heating rates $\left(\beta: 2,5,10,25\right.$ and $\left.75^{\circ} \mathrm{C} \mathrm{min}^{-1}\right)$ up to a maximum temperature of $600{ }^{\circ} \mathrm{C}$ with a hold time of $15 \mathrm{~min}$. The inert atmosphere was set with a nitrogen flow rate of $30 \mathrm{ml} \mathrm{min.}{ }^{-1}$. Samples were analysed in triplicate.

\subsection{Fast pyrolysis experiments}

The fast pyrolysis tests were performed in a $1 \mathrm{~kg} \mathrm{~h} .{ }^{-1}$ continuous bubbling fluidised bed reactor at the Bioenergy Research Group (BERG, Aston University). The system is composed of the feeding system, the main pyrolysis reactor chamber and products' collection chambers. The biomass feed rate was $650 \mathrm{~kg} \mathrm{~h}^{-1}$ and was dependent on biomass density. The feeding system was an air-tight hopper with a nitrogen purge that fed into the lower part of the fluid bed reactor. The reactor bed material was $1 \mathrm{~kg}$ of sieved quartz sand with a particle size between 600 and $710 \mu \mathrm{m}$. The reactor was fluidized using pre-heated nitrogen as carrier gas (17 dm3 min-1). It was pre-heated in a chamber below the main reactor chamber. The hot vapour residence time was below $1.5 \mathrm{~s}$ in the reactor and associated hot pipework and cyclones. When the gas left the reactor it passed through two heated cyclones and the char was deposited on a chamber for its collection. After the cyclones the pyrolysis vapours from the gas condensed in a cooled quench column in contact with ISOPAR ${ }^{\mathrm{TM}}$ (ISOPAR V. CAS number: 64742-46-7. Supplier: Multisol Limited). A temperature between 20 and $25{ }^{\circ} \mathrm{C}$ was kept with a water jacket that surrounded the quench column. The aerosols remained in a wet walled electrostatic precipitator $(20 \mathrm{kV}$ and $0.2 \mathrm{~mA})$, flushed with ISOPAR ${ }^{\mathrm{TM}}$. Following the electrostatic precipitator the gas passed through a water cooled condenser $\left(0-15^{\circ} \mathrm{C}\right)$, two dry iceacetone condensers (at $-70^{\circ} \mathrm{C}$ ), a cotton wool filter, and $250 \mathrm{~g}$ of silica gel (silica gel orange, CAS number: 112926-00-8, 2-5 mm). An on-line Varian CP 4900 Micro-GC microgas chromatograph with a thermal conductivity detector (TCD) and two columns (Varian CP-5AMolsieve and CP-PortaPLOT) were used for the analysis of noncondensable gases. The gas (nitrogen and product gas) was analysed every $150 \mathrm{~s}$, and its final composition was the average of readings. Temperatures were measured with K-type 
thermocouples joined to a Microlink 751 ADC unit and recorded using Windmill data logging software. System pressures were measured to identify any blockages or leaks. Mass balances (wt.\% on dry basis) were calculated based on mass of biomass processed and biooil, char and non-condensable gases. Further details of the reactor configuration are described elsewhere [8].

Acceptable mass balance closures were achieved for all temperatures ( $>88 \%)$. Previous tests have ranged between 84.76 to $94.24 \mathrm{wt} \%$ in the same equipment [8]. Losses in the mass balance are thought to be caused by: the size of the reactor (semi-pilot plant); the complexity of the system; errors in water content analysis, weight measurement and gas analysis caused by heavily diluted pyrolysis gases (content of nitrogen carrier gas above $95 \%$ in the gas stream).

\subsection{Analysis techniques}

\subsubsection{Feedstock and char characterisation}

Ultimate composition analysis for the feedstock and char obtained after fast pyrolysis were performed using a Carlo-Erba 1108 elemental analyser to determine the chemical elements: C, H and N, according to the standard ASTM 5373 [15]. Prior to analysis the materials were dried at $105 \pm 2{ }^{\circ} \mathrm{C}$ for $24 \mathrm{~h}$ in order to remove moisture. The analysis were done in duplicates and the average value was determined. Oxygen content was obtained by difference.

The feedstock was also analysed for proximate composition (total moisture, volatile matter and ashes) according to the standard ASTM D3302 [16], the norm UNE 3219 UNEEN ISO [17] and the standard ASTM E1755-01(2015) [18]. Moisture content was measured by duplicate in a Sartorious MA 35 moisture analyser. Ash content was determined with a Carbolite AAF1100 furnace, being previously dried at $105 \pm 2{ }^{\circ} \mathrm{C}$ for $24 \mathrm{~h}$ in order to remove

moisture content. Inorganic content ( $\mathrm{Al}, \mathrm{Ca}, \mathrm{Fe}, \mathrm{K}, \mathrm{Mg}, \mathrm{Na}, \mathrm{P}$ and $\mathrm{Si}$ ) was determined by acid digestion and carried out in an induced coupled plasma emission spectrometer Varian Vista MPX ICP-OES done in an external lab. 
Char ash content was determined by combustion with a thermobalance in a stable air atmosphere, with a heating rate of $5{ }^{\circ} \mathrm{C}$ min. ${ }^{-1}$ with a maximum temperature of $575{ }^{\circ} \mathrm{C}$, held for $15 \mathrm{~min}$ at this temperature.

The high heating value (HHV) was calculated according to Frield et al., (2005) [19].

\subsubsection{Gas fraction characterisation}

The gas fraction was analysed by an on-line Varian CP 4900 Micro-GC microgas chromatograph. A thermal conductivity detector (TCD) and two columns, Varian CP-5A Molsieve and a Varian CP-PoraPLOT, were used to analyse the non-condensable gases (hydrogen, carbon monoxide, carbon dioxide, methane, ethane, ethene, propane, propene, and n-butane). Samples of non-condensable gases were taken at intervals of $150 \mathrm{~s}$ for the entire length of fast pyrolysis experiment. Thus, the global gas composition for each run was calculated from the mean value of the entire data detection of each gaseous specie. The lower heating value was obtained theoretically from the norm UNE-EN-ISO 6976 [20] based on the volumetric composition and the heating value of each gaseous specie at $0{ }^{\circ} \mathrm{C}$.

\subsubsection{Bio-oil characterisation}

\subsubsection{Ultimate composition analysis and heating value determination}

Ultimate composition analysis was determined on a wet basis following the procedure described in section 2.4.1 for solids. The high heating value was also determined according to Frield et al., (2005) [19].

\subsubsection{Water content, $\mathrm{pH}$, and dynamic viscosity determination}

The water content of liquid products was determined by volumetric Karl-Fischer (KF) titration using a Mettler Toledo V20 KF titrator. Hydranal (R) K and Hydranal (R) Composite $5 \mathrm{~K}$ were used as a medium and a titrant respectively. Prior to analysis, the KF instrument was calibrated with HPLC grade water and the system flushed with working medium between each sample analysis. The analyses were done in triplicate and average values were taken. 
Bio-oil acidity was calculated by means of a $\mathrm{pH}$ analysis using a Sartorius $\mathrm{pH}$-meter according to the standard ASTM E70 - 07 [21].

A Brookfield Viscometer model DV-II + pro rotational viscometer was used to measure the dynamic viscosity of all bio-oil samples. Prior to measurements, the viscometer was calibrated with a 0.0045 Pas Brookfield silicone viscosity calibration standard $( \pm 1 \%$ accuracy; repeatability $0.2 \%$ full-scale range). The viscosity of the bio-oils were measured at $40 \pm 0.1{ }^{\circ} \mathrm{C}$ when the shear rates identified Newtonian behavior in the bio-oil. Different spindles (CS4-18 and CS4-34) were used as appropriate using an initial speed of 5 rpm, increased every minute by $0.5 \mathrm{rpm}$ for 120 minutes.

\subsubsection{Gel permeation chromatography (GPC) for molecular weight determination}

Gel permeation chromatography PL-GPC-50 was used to measure the average molecular weight distribution of the bio-oil. The GPC has two columns Agile PL gel (300 m length x $7.5 \mathrm{~mm}$ wide) with a pore size of $5 \mu \mathrm{m}$. Approximately $50 \mathrm{mg}$ of bio-oil was diluted in Tetrahydrofuran (HPLC grade): in a 1:20 v/v proportion. The THF solution of bio-oil was first filtered using filter paper of $0.2 \mu \mathrm{m}$ to remove any solid that could block the column. Then, $100 \mu \mathrm{l}$ of bio-oil solution was automatically by an injector PL-AS RT setting, whilst the GPC was maintained at $40{ }^{\circ} \mathrm{C}$. The parameters which were measured were the number of average molar mass $(\mathrm{Mn})$, the average molecular weight distribution $(\mathrm{Mw})$ and the polydispersity index $(\mathrm{PD}=\mathrm{Mw} / \mathrm{Mn})$.

\subsubsection{Compound identification and quantification: liquid-GC/MS}

For the identification and quantification of the constituents of each bio-oil sample, a PerkinElmer TurboMass Gold GC-MS/FID system was used. The GC-MS/FID system has a PerkinElmer Elite-1701 column (crossbond: $14 \%$ cyanopropylphenyl and $85 \%$ dimethyl polysiloxane) with $60 \mathrm{~m}$ length, $0.25 \mathrm{~mm}$ interior diameter and $0.25 \mathrm{~mm}$ gross. GC samples were prepared by mixing bio-oil and GC grade ethanol (1:5 v/v). A GC sample of $1 \mathrm{ml}$ was injected onto the GC column via an injection port at $280{ }^{\circ} \mathrm{C}$, with 1:25 split ratio. Separation was carried out on the column. The GC oven was programmed with the following steps: held constant at $45{ }^{\circ} \mathrm{C}$ for $5 \mathrm{~min}$, then ramped at $5{ }^{\circ} \mathrm{C} \mathrm{min.}{ }^{-1}$ to $250{ }^{\circ} \mathrm{C}$ and held for $5 \mathrm{~min}$. During 
the test, a constant flow of $2 \mathrm{ml} \mathrm{min.}{ }^{-1}$ of helium was used as carried gas. Mass spectra was obtained using $70 \mathrm{eV}$ ionisation energy within a molecular mass range of $\mathrm{m} / \mathrm{z} 35$ to 300 . The main peaks were identified using the NIST98 MS library and from literature assignments [22], [23] [24, 25], [26].

\subsubsection{Bio-oil accelerated storage experiment}

To simulate one year bio-oil degradation at ambient temperature, the bio-oil were subjected to an accelerated storage experiment according to [27]. $75 \mathrm{ml}$ of each bio-oil was placed in a $100 \mathrm{ml}$ glass bottle previously dried at $105{ }^{\circ} \mathrm{C}$ for $4 \mathrm{~h}$ in order to remove all moisture. The lids were replaced on the bottles and placed in an oven at $80{ }^{\circ} \mathrm{C}$ for $24 \mathrm{~h}$. After 10 minutes, the bottle lids were re-tightened. After $24 \mathrm{~h}$ the bio-oil samples were removed from the oven and left to cool. The molecular weight distribution (Mw), water content (W) and viscosity (V) were re-measured and a stability index was calculated using equations equations (eq) 1, 2 and 3 respectively.

$\Delta \mathrm{MwSTABILITY}=(\mathrm{MwAGED}-\mathrm{MwFRESH}) / \mathrm{MwFRESH} \quad$ eq. 1

$\Delta$ WSTABILITY $=($ WAGED- WFRESH $) /$ WFRESH eq. 2

$\triangle$ VSTABILITY $=($ VAGED- VFRESH $) /$ VFRESH $\quad$ eq. 3

Where:

FRESH - value before accelerated storage experiment $(0 \mathrm{~h})$;

AGED - value after accelerated storage experiment $(24 \mathrm{~h})$.

A zero value of the index points to a stable bio-oil that does not change its molecular weight distribution, water content or viscosity with heating or time; a value between 1-0 or 0-(-1) value indicates an increment or detriment in average molecular weight, water content or viscosity respectively than initial characteristics of bio-oils previous to storage tests.

\section{RESULTS AND DISCUSSION}

\subsection{Biomass characterisation}

Biomass characterisation is relevant to identify the effect of biomass composition in fast pyrolysis processing. Table 1 summarised the rape straw biomass composition. Rape straw 
$\mathrm{C}, \mathrm{H}, \mathrm{N}$ and $\mathrm{O}$ values were found similar to $47 \%, 6 \%,<3 \%$ and $54 \%$ average values (dry as free basis) respectively from 150 different biomass resources [28]. Only oxygen content was distant about $7 \%$ lower. Comparing moisture, volatile matter and ashes average values from Garcia et al., (2012) [28], moisture was found to be $15 \%$ lower and the volatile matter had nearly values of $70 \%$ volatile matter. The ash content fell in the $2-10 \%$ range. Moisture and ash contents are usually more variable due to growing conditions and harvesting [29]. In addition, rape straw inorganic content was characterised for high levels of $\mathrm{K}, \mathrm{Ca}$ and $\mathrm{P}$ which are typical values of agroresidual materials [30].

Figure 1 shows the thermogravimetric profile of rape straw at different heating ramps. According to Carrier et al., (2011) [31], the thermogravimetric profile is an indicator of cellulose, hemicellulose and lignin relative content and their individual behavior can be determined from the shape of the thermogravimetric profile. Rape straw has an unique peak of mass loss rate and its maximum decomposition rate correlates well with the principal cellulose peak found by other authors $\left(342{ }^{\circ} \mathrm{C} ; 10{ }^{\circ} \mathrm{C} \mathrm{min} .{ }^{-1}\right)$, indicative of high cellulose content. This result is in line with a previous study where rape straw was composed of $45 \%$ of cellulose, $19 \%$ of hemicellulose and $18 \%$ of lignin [32]. It is notable that the heating ramp affects the rate of mass loss and the maximum rate of mass loss temperature, being elevated at higher heating rates. This behavior is an important factor for fast pyrolysis as the higher heating rate releases volatiles quickly and promotes less char formation, from $34.80 \%\left(2{ }^{\circ} \mathrm{C}\right.$ $\left.\min ^{-1}\right)$ to $22.89\left(75^{\circ} \mathrm{C} \min ^{-1}\right)$.

\subsection{Fast pyrolysis processing}

The fast pyrolysis mass balances for rape straw processed at 450 to $550{ }^{\circ} \mathrm{C}$ are summarised in Figure 2. When the fast pyrolysis temperature increases there was an increase in gas yield (from 14 wt. \% to 18 wt. \%), a decrease in char yield (from 25 wt. \% to 23 wt. $\%)$ and a decrease in bio-oil yield (from $36 \mathrm{wt}$. \% to $25 \mathrm{wt}$ \%). The most representative temperature for fast pyrolysis is usually $510^{\circ} \mathrm{C}$ [1] because it results in the highest bio-oil yield and the lowest char and non-condensable vapours yields. Nonetheless, there was an increase in water formation at $510{ }^{\circ} \mathrm{C}$ but not a char nor gas fraction increment, decreasing bio-oil yield. In addition, bio-oil at 450 and $480{ }^{\circ} \mathrm{C}$ resulted in a single phase product, but at higher temperatures $\left(510\right.$ and $\left.550{ }^{\circ} \mathrm{C}\right)$ the increment of reaction water caused phase 
separation, as it is shown in figure 3a. It is likely that the high inorganic content of this biomass resulted in a catalytic effect on the fast pyrolysis products. According to Nowakowski \& Jones, (2008) [25] K provokes the cracking of the glucosidic unit of cellulose by depolimerisation and fragmentation to lower molecular weight compounds resulting in more water formation, $\mathrm{CO}_{2}$, methane, acetone, acetic acid, formic acid, glyoxal, hydroxyacetaldehyde, etc. Furthermore, the thermogravimetric analysis showed high cellulose content in rape straw; and cellulose normally yields high liquid yields [33]. So the catalytic effect was relevant in the bio-oil and dependent on pyrolysis temperature.

The maximum bio-oil yield was accounted at $450{ }^{\circ} \mathrm{C}$ with a yield value of 41 wt. \% (removing the losses of the balances). This yield was nearly $10 \%$ less than the bio-oil yield from fast pyrolysis of cellulose [1], indicating that the catalytic effect of $\mathrm{K}$ also affected at low temperatures.

\subsection{Gas characterisation}

The main non-condensable gases from fast pyrolysis of lignocellulosic material are carbon dioxide $\left(\mathrm{CO}_{2}\right)$ carbon monoxide $(\mathrm{CO})$, light-hydrocarbon $\left(\mathrm{CH}_{4}\right.$ and $\left.\mathrm{C}_{2}-\mathrm{C}_{4}\right)$ and hydrogen $\left(\mathrm{H}_{2}\right)$ [34]. Figure 4 shows the different gaseous species composition trend at the fast pyrolysis temperature range of $450-550{ }^{\circ} \mathrm{C} . \mathrm{CO}_{2}$ was the main component in the entire range of temperatures, at concentrations higher than $40 \%$ of the total non-condensable gas yield. According to Tröguer et al., (2013) [35] high release of $\mathrm{CO}_{2}$ correlates well with biomass that has high inorganic content. The second main component was CO that showed an emission peak of $36 \%$ of the total non-condensable gas yield at $480{ }^{\circ} \mathrm{C}$. This peak points to an increased rate of cracking reactions of the carbonyl and carboxyl groups of cellulose [34]. $\mathrm{CO} / \mathrm{CO}_{2}$ ratio is an indicator of product yield changes. In fact, an increase in $\mathrm{CO}$ and a decrease in $\mathrm{CO}_{2}$ indicate an increase in condensable vapours and a decrease in char, gas and water yields, even being a controlling variable in fast pyrolysis processes [35]. It is considered that the biomass inorganic matter promoted this stage at lower temperatures rather than at $510^{\circ} \mathrm{C}$ (most representative temperature for fast pyrolysis). The light hydrocarbon fraction $\left(\mathrm{C}_{2}-\mathrm{C}_{4}\right)$ was higher at lower temperatures $\left(450-480{ }^{\circ} \mathrm{C}\right)$ and the $\mathrm{CH}_{4}$ was higher at higher temperatures $\left(510-550^{\circ} \mathrm{C}\right)$, because lignin and cellulose released it from the aromatic rings of its constituents at this interval of temperatures [36]. The high $\mathrm{CH}_{4}$ at 510 and $550^{\circ} \mathrm{C}$ 
temperatures can be also explained from the catalytic effect of potassium over cellulose, found by Nowakowski \& Jones, (2008) [25]. Low $\mathrm{H}_{2}$ yields were produced at all fast pyrolysis temperatures ranges, as significant hydrogen release is not evident until fast temperatures are greater than $550{ }^{\circ} \mathrm{C}$ [36]. Low hydrogen yields are produced also because of the low lignin content of the rape straw which usually release more $\mathrm{H}_{2}$ [34].

The LHV of the gases were: $16.72\left(450{ }^{\circ} \mathrm{C}\right), 17.51\left(480{ }^{\circ} \mathrm{C}\right), 21.57\left(510{ }^{\circ} \mathrm{C}\right)$ and 19.27 $\left(550{ }^{\circ} \mathrm{C}\right) \mathrm{MJ} \mathrm{m}^{-3}$. The gas fraction with the highest heating value was produced at the fast pyrolysis temperature of $510^{\circ} \mathrm{C}$, this is due to a higher yield of light hydrocarbons, lower $\mathrm{CO}$ yields and the lowest $\mathrm{CO}_{2}$ yield of all fast pyrolysis temperature ranges.

\subsection{Char characterisation}

Table 2 shows the proximate and ultimate analyses, ash content and HHV value of the char from 450 to $550{ }^{\circ} \mathrm{C}$ fast pyrolysis temperatures. As the fast pyrolysis temperature increased, the ash content increased, especially at $550{ }^{\circ} \mathrm{C}$, probably caused by a severe devolatilisation promoted by the higher reaction temperature. The carbon content increased as the fast pyrolysis temperature increased. There were also a decrease in nitrogen which could have been released as $\mathrm{N}_{2}$ gas. Hydrogen decreased with temperature, being higher the detriment at $510^{\circ} \mathrm{C}$ because of the higher reaction water formation in the liquid fraction from the catalytic effect of $\mathrm{K}$. Oxygen decreased more at $550{ }^{\circ} \mathrm{C}$ due to the highest release of $\mathrm{CO}_{2}$ in the gas fraction at this temperature.

The heating value was maintained almost constant between 23-24 MJ kg. ${ }^{-1}$ at all fast pyrolysis temperatures. At higher fast pyrolysis temperatures there was a higher concentration of carbon but the ash content from the biomass with high inorganic matter also increased given the further devolatilisation caused by the higher temperature, thereby reducing the overall heating value.

\subsection{Bio-oil characterisation}

Table 3 shows the ultimate analysis, high heating value, water content, $\mathrm{pH}$, viscosity and the average molecular weight distribution of each bio-oil at each fast pyrolysis temperature. Difference in bio-oil phases were found with some being single phase (SP), 
and others being phase separated, a light phase (LP) and heavy phase (HP). At 450 and 480 ${ }^{\circ} \mathrm{C}$ pyrolysis temperatures, bio-oil was a single phase. At higher temperatures the bio-oil was phase separated given the catalytic effect of $\mathrm{K}$ that promoted high water reaction at those temperatures.Thus, the carbon content being concentrated in the heavy phase, the light phase had a high water content. The high water content in the light phase resulted in increased hydrogen and oxygen content when compared to the heavy phase or the single phase bio-oils. The nitrogen content was concentrated in the heavy phase, thus nitrogen tended to be linked to heavy polymeric structures. The HHV was higher at $480{ }^{\circ} \mathrm{C}(19.23$ $\mathrm{MJ} / \mathrm{kg})$ than at $450{ }^{\circ} \mathrm{C}(16.11 \mathrm{MJ} / \mathrm{kg})$ in the SP bio-oils. It is likely that their individual condensable vapours had higher HHV, promoted by favorable cracking reactions enhanced by the inorganic matter. Despite of the higher carbon content of the HP bio-oil at $550{ }^{\circ} \mathrm{C}$ the oxygen content made its HHV remained low. Common HHV values of bio-oil are within the range of 16-19 $\mathrm{MJ} / \mathrm{kg}$ [13].

Table 3 also showed the physical features of bio-oils from fast pyrolysis of rape straw. Single phases from 450 and $480{ }^{\circ} \mathrm{C}$ fast pyrolysis temperature are maintained in middle values of water content (35.92\%) (33.69\%), viscosity (876 Pa.s) (1138.5 Pa.s) and average molecular weight distribution $(484.5 \mathrm{~g} / \mathrm{mol})$ and $(570 \mathrm{~g} / \mathrm{mol})$ respectively than light and heavy phases. Those values of water and viscosity from 450 and $480{ }^{\circ} \mathrm{C}$ bio-oils are almost within the common bio-oil ranges of water (15-30 wt\%) [13] and viscosity (1000-9000 Pa.s) [37]. Those SP bio-oils had a lineal relation between these parameters (water content, viscosity and molecular weight distribution) as other authors reported [27] but it was not remained in separated phases. The HP bio-oils contained heavy molecular mass compounds identified by an increased average molecular weight distribution. That heavy molecular compounds had high viscosity that indicated high polimerisation reactions caused by the catalytic effect of $\mathrm{K}$ at high temperatures forming high water content that remained in the light phase. Then, the linear relation between water content, viscosity and molecular weight was not conserved.

The $\mathrm{pH}$ content was higher than common values for bio oil $(-2.5)$ [37], therefore containing lower acidic compounds. The fast pyrolysis temperature of $550{ }^{\circ} \mathrm{C}$ resulted in the highest $\mathrm{pH}$ bio-oil. It is likely that acid compounds reacted by esterification and 
transesterification reactions producing water and long ester chains that would be in accordance with the higher water content gained in the light phases and the higher average molecular weight in the heavy phase.

\subsection{Energy distribution in the pyrolysis fractions}

Figure 5 shows the energy distribution in the fast pyrolysis fractions produced at each fast pyrolysis temperature. The energy distribution depends on the mass yield and HHV of each fraction. According to figure 2, the char mass yield decreased when the fast pyrolysis temperature increased, whilst their HHV increased due to further char devolatilisation caused by the temperature increment. From 450 to $510{ }^{\circ} \mathrm{C}$ the char decreased in energy yield. However, the char produced at $550{ }^{\circ} \mathrm{C}$ had high heating value $(24.10 \mathrm{MJ} / \mathrm{kg})$ due to a high grade of carbonisation and the lowest oxygen content $(10.75 \%)$. Thus, the HHV affected the overall energy content, being incremented.

The highest mass yield of bio-oil was obtained at $450{ }^{\circ} \mathrm{C}$, but the highest energy yield was obtained at $480{ }^{\circ} \mathrm{C}$ due to very similar mass yield as $450{ }^{\circ} \mathrm{C}(-1 \%$ lower $)$ but a higher HHV. Gas fraction energy content was more relevant at $510^{\circ} \mathrm{C}$ where it was enriched in hydrocarbon (methane and $\mathrm{C}_{2}-\mathrm{C}_{4}$ hydrocarbons) incrementing its $\mathrm{HHV}$ coming from the conjunction effect of temperature and the catalysed effect of $\mathrm{K}$ over cellulose. This trend is repeated at higher fast pyrolysis temperatures increasing in energy yield.

\subsection{Bio-oil chemical composition}

Bio-oil produced at $480{ }^{\circ} \mathrm{C}$ was selected as reference because it was single phase and had the highest energy content. Table 5 shows the main compounds identified in the bio-oil. A total of $52 \%$ of the area has been identified. From the $52 \%$ of identified compounds 23 $\%$ of the chemical compounds are phenols. The presence of this group are typically lignin indicators. Nonetheless, lignin was not the main component of the rape straw. It is proposed they come from the catalytic effect of $\mathrm{K}$ over cellulose together with the high the bio-oil reaction water. Nowakowski \& Jones, (2008) [25] proposed that K decomposes cellulose via a different reaction pathway, decreasing anhydrosugars and furanics and promoting phenols and cyclopentane derivatives that has been found in the GC-MS analysis: 2-Methoxyphenol 
(guaiacol) (4), 2- Methoxy-4-methlyl-phenol (creosol) (6) and 2,4 Dimethoxy-phenol (syringol) (10) and 2-Hydroxy-3-methyl-2-cyclopenten-1-one (corylon) (3) and 3-Ethyl-2hydroxy-2-cyclopenten-1-one (5) compounds. In addition, P could also have a catalytic effect on the fast pyrolysis reaction promoting levoglucosanone (18) through regrouping and dehydratation reactions of the levoglucosan [24]. Moreover, this premise is supported by the formation of desaspidinol, metoxiphenols, dimetoxiphenols and trietoxiphenols $(20,15,17$ and 19) that are promoted by the catalytic effect of $P$ on lignin [24]. It is therefore-assumed that $\mathrm{K}$ and $\mathrm{P}$ catalysed the fast pyrolysis reaction provoking natural selection of phenols and reducing typical bio-oil compounds such as furfural groups which were not found in the identified compounds.

\subsection{Bio-oil storage test}

To study the bio-oil degradative behavior an accelerated storage experiment was performed, and figure $3 \mathrm{~b}$ shows the bio-oils separation phase behaviors. It can be seen that single phase bio-oils from 450 and $480{ }^{\circ} \mathrm{C}$ fast pyrolysis temperature have become phase separated and that bio-oils that were already phase separated $\left(510\right.$ and $\left.550{ }^{\circ} \mathrm{C}\right)$ have an increased heavy phase fraction to values higher that $60 \%$. Table 4 shows the bio-oils immediate analysis, the HHV and the stability indices for water content, viscosity, average molecular weight distribution, $\mathrm{pH}$ and polydispersity. Light phases were concentrated in hydrogen and oxygen due to more water content whilst heavy phase were concentrated in carbon content. The oxygen content was still high in the heavy phase resulting in lower than expected heating values. Nitrogen was linked to heavy compounds as it was found previously.

The stability indices showed the overall bio-oil water content did not almost increased. This fact may be explained because the water formed may be used in the formation of new compounds and a redistribution of the overall water content in the different phases (LP and HP). Furthermore, molecular weight distribution increased from 21 to $45 \%$ in the heavy phase and in most of the bio-oil light phases (3 to $26 \%$ ). Thus, it is expected that the phase

separation of bio-oils were caused by the difference in properties of viscosity and average molecular weight distribution of newly formed compounds. It is also probably that if water was formed during the accelerated storage experiment it would take part in new reactions. 
According to Chen et al. (2014) [38] the main reactions during storage were: esterification reactions (alcohols with organic acids forming esters and water), transesterification reactions (exchanging of alcohol and acid groups in a mixture of two or more esters), homopolymerization reactions (aldehydes reacting with each other to form polyacetal oligomers and polymers), hydration reactions (aldehydes or ketones mixed with water react to form hydrates), etc. During this process the samples tended to be acidified in low range. Finally, the polydispersity index highlights that the bio-oils are composed of a higher number

of molecules than before accelerated storage, as the Mw increased ant PD remained almost constant. Thus, indicating an increase in the number of molecules.

\section{CONCLUSIONS}

It has been demonstrated how the fast pyrolysis temperature and $\mathrm{K}$ and $\mathrm{P}$ content of ashes interact in the pyrolysis reaction and affect the chemical composition and physical characteristics of bio-oil. Despite the high potassium content of the feed, the bio-oil showed common bio-oils physico-chemical features, at $480{ }^{\circ} \mathrm{C}$. Although the yield was not high (39.65 wt. \%), non-separation phase was achieved, giving a chance of using high ash biomasses in fast pyrolysis and upgrading. Further work should be done to assess bio-oil upgrading if "energy from agro-waste" is the objective of getting renewable fuels. It has been perceived that potassium has a catalytic influence on the bio-oil composition, provoking natural selection of phenols in the bio-oil, pointing it could be also possible to study their use for the resin industry.

The energy distribution between all fast pyrolysis products has also shown the relevance of the solid fraction (char). Thus, char should also be considered a relevant coproduct to take into account for fast pyrolysis of high inorganic biomass given their high yield and energy content. They can be reused as a source of energy for the production of bio-oil and even for its upgrading that could benefit the feasibility of the process.

\section{ACKNOWLEDGEMENTS}

The authors wish to thank the Biofuels Research Infrastructure for Sharing Knowledge (BRISK) for funding Natalia Gómez-Marín in 2012 to undertake this research. 


\section{REFERENCES}

[1] A. V. Bridgwater, "Review of fast pyrolysis of biomass and product upgrading," Biomass and Bioenergy, vol. 38, no. 0, pp. 68-94, 3// 2012.

[2] S. V. Vassilev, D. Baxter, L. K. Andersen, C. G. Vassileva, and T. J. Morgan, "An overview of the organic and inorganic phase composition of biomass," Fuel, vol. 94, no. 0, pp. 1-33, 4// 2012.

[3] D. Mohan, C. U. Pittman, and P. H. Steele, "Pyrolysis of Wood/Biomass for Bio-oil: A Critical Review," Energy \& Fuels, vol. 20, no. 3, pp. 848-889, 2006/05/01 2006.

[4] D. Shen, W. Jin, J. Hu, R. Xiao, and K. Luo, "An overview on fast pyrolysis of the main constituents in lignocellulosic biomass to valued-added chemicals: Structures, pathways and interactions," Renewable and Sustainable Energy Reviews, vol. 51, pp. 761-774, 11// 2015.

[5] C. E. Greenhalf, D. J. Nowakowski, A. B. Harms, J. O. Titiloye, and A. V. Bridgwater, "A comparative study of straw, perennial grasses and hardwoods in terms of fast pyrolysis products," Fuel, vol. 108, no. 0, pp. 216-230, 6// 2013.

[6] S. V. Vassilev, D. Baxter, L. K. Andersen, and C. G. Vassileva, "An overview of the composition and application of biomass ash. Part 1. Phase-mineral and chemical composition and classification," Fuel, vol. 105, no. 0, pp. 40-76, 3// 2013.

[7] O. D. Mante, T. E. Amidon, A. Stipanovic, and S. P. Babu, "Integration of biomass pretreatment with fast pyrolysis: An evaluation of electron beam (EB) irradiation and hot-water extraction (HWE)," Journal of Analytical and Applied Pyrolysis, vol. 110, pp. 44-54, 11// 2014.

[8] S. W. Banks, D. J. Nowakowski, and A. V. Bridgwater, "Fast pyrolysis processing of surfactant washed Miscanthus," Fuel Processing Technology, vol. 128, pp. 94-103, Dec 2014.

[9] T. Wigley, A. C. K. Yip, and S. Pang, "The use of demineralisation and torrefaction to improve the properties of biomass intended as a feedstock for fast pyrolysis," Journal of Analytical and Applied Pyrolysis, vol. 113, pp. 296-306, 5// 2015.

[10] S. D. Stefanidis, E. Heracleous, D. T. Patiaka, K. G. Kalogiannis, C. M. Michailof, and A. A. Lappas, "Optimization of bio-oil yields by demineralization of low quality biomass," Biomass and Bioenergy, vol. 83, pp. 105-115, 12// 2015.

[11] A. Demirbas, "Effects of temperature and particle size on bio-char yield from pyrolysis of agricultural residues," Journal of Analytical and Applied Pyrolysis, vol. 72, no. 2, pp. 243-248, 2004. 
[12] N. Gómez, J. G. Rosas, J. Cara, O. Martínez, J. A. Alburquerque, and M. E. Sánchez, "Slow pyrolysis of relevant biomasses in the Mediterranean basin. Part 1. Effect of temperature on process performance on a pilot scale," Journal of Cleaner Production, no. 0, 2014.

[13] Q. Zhang, J. Chang, T. Wang, and Y. Xu, "Review of biomass pyrolysis oil properties and upgrading research," Energy Conversion and Management, vol. 48, no. 1, pp. 87-92, 2007.

[14] ASTM E1131-03, Standard Test Method for Compositional Analysis by Thermogravimetry, 2003.

[15] ASTM D5373-16, Standard Test Methods for Determination of Carbon, Hydrogen and Nitrogen in Analysis Samples of Coal and Carbon in Analysis Samples of Coal and Coke, 2016.

[16] ASTM D3302 / D3302M-17, Standard Test Method for Total Moisture in Coal, 2017.

[17] UNE-EN ISO 18123:2016, Solid biofuels - Determination of the content of volatile matter 2016.

[18] ASTM E1755-01(2015), Standard Test Method for Ash in Biomass, 2015.

[19] A. Friedl, E. Padouvas, H. Rotter, and K. Varmuza, "Prediction of heating values of biomass fuel from elemental composition," Analytica Chimica Acta, vol. 544, no. 12, pp. 191-198, 7/15/ 2005.

[20] UNE-EN ISO 6976:2005, Natural gas - Calculation of calorific values, density, relative density and Wobbe index from composition (ISO 6976:1995 including Corrigendum 1:1997, Corrigendum 2:1997 and Corrigendum 3:1999), 2005.

[21] ASTM E70-07(2015), Standard Test Method for $\mathrm{pH}$ of Aqueous Solutions With the Glass Electrode,, 2015.

[22] P. K. Kanaujia, Y. K. Sharma, M. O. Garg, D. Tripathi, and R. Singh, "Review of analytical strategies in the production and upgrading of bio-oils derived from lignocellulosic biomass," Journal of Analytical and Applied Pyrolysis, vol. 105, no. 0, pp. 55-74, 1// 2014.

[23] G. Jiang, D. J. Nowakowski, and A. V. Bridgwater, "Effect of the Temperature on the Composition of Lignin Pyrolysis Products," Energy \& Fuels, vol. 24, no. 8, pp. 44704475, 2010/08/19 2010.

[24] D. J. Nowakowski, C. R. Woodbridge, and J. M. Jones, "Phosphorus catalysis in the pyrolysis behaviour of biomass," Journal of Analytical and Applied Pyrolysis, vol. 83, no. 2, pp. 197-204, 11// 2008. 
[25] D. J. Nowakowski and J. M. Jones, "Uncatalysed and potassium-catalysed pyrolysis of the cell-wall constituents of biomass and their model compounds," Journal of Analytical and Applied Pyrolysis, vol. 83, no. 1, pp. 12-25, 9// 2008.

[26] C. Saiz-Jimenez and J. W. De Leeuw, "Lignin pyrolysis products: Their structures and their significance as biomarkers," Organic Geochemistry, vol. 10, no. 4-6, pp. 869876, // 1986.

[27] A. Oasmaa, E. Leppämäki, P. Koponen, J. Levander, and E. Tapola, Physical Characterisation of Biomass-Based Pyrolysis Liquids: Application of Standard Fuel Oil Analyses (VTT publications). Technical Research Centre of Finland, 1997.

[28] R. García, C. Pizarro, A. G. Lavín, and J. L. Bueno, "Characterization of Spanish biomass wastes for energy use," Bioresource Technology, vol. 103, no. 1, pp. 249258, 1// 2012.

[29] P. McKendry, "Energy production from biomass (part 1): overview of biomass," Bioresource Technology, vol. 83, no. 1, pp. 37-46, 2002.

[30] S. V. Vassilev, D. Baxter, L. K. Andersen, and C. G. Vassileva, "An overview of the chemical composition of biomass," Fuel, vol. 89, no. 5, pp. 913-933, 5// 2010.

[31] M. Carrier et al., "Thermogravimetric analysis as a new method to determine the lignocellulosic composition of biomass," Biomass and Bioenergy, vol. 35, no. 1, pp. 298-307, 1// 2011.

[32] P. Chartier, G. L. Ferrero, U. M. Henius, S. Hultberg, J. Sachau, and M. Wiinblad, E. Ltd, Ed. Biomass for Energy and the Environment (Biomass for Energy and the Environment). Oxford: Pergamon, 1996.

[33] S. D. Stefanidis, K. G. Kalogiannis, E. F. Iliopoulou, C. M. Michailof, P. A. Pilavachi, and A. A. Lappas, "A study of lignocellulosic biomass pyrolysis via the pyrolysis of cellulose, hemicellulose and lignin," Journal of Analytical and Applied Pyrolysis, vol. 105, no. 0, pp. 143-150, 1// 2014.

[34] H. Yang, R. Yan, H. Chen, D. H. Lee, and C. Zheng, "Characteristics of hemicellulose, cellulose and lignin pyrolysis," Fuel, vol. 86, no. 12-13, pp. 1781-1788, 2007.

[35] N. Tröger, D. Richter, and R. Stahl, "Effect of feedstock composition on product yields and energy recovery rates of fast pyrolysis products from different straw types," Journal of Analytical and Applied Pyrolysis, vol. 100, no. 0, pp. 158-165, 3// 2013.

[36] F.-X. Collard and J. Blin, "A review on pyrolysis of biomass constituents: Mechanisms and composition of the products obtained from the conversion of cellulose, 
hemicelluloses and lignin," Renewable and Sustainable Energy Reviews, vol. 38, no. 0, pp. 594-608, 10// 2014.

[37] A. O. C. Peacocke, "Properties and fuel use of biomass-derived fast pyrolysis liquids.A guide," ed. VTT PUBLICATIONS 731, 2010.

[38] D. Chen, J. Zhou, Q. Zhang, and X. Zhu, "Evaluation methods and research progresses in bio-oil storage stability," Renewable and Sustainable Energy Reviews, vol. 40, no. 0, pp. 69-79, 12// 2014. 